\title{
Fostering Trust, Transparency, Satisfaction and Participation Amidst COVID-19 corruption: Does the Civil Society Matter? - Evidence from Ghana
}

\author{
Vincent Ekow Arkorful ${ }^{1}$ (D) Nurudeen Abdul-Rahaman ${ }^{2}$. \\ Hidaya Sungjun Ibrahim $^{3}$. Vincent Ansah Arkorful ${ }^{4}$
}

Accepted: 4 November 2021 / Published online: 24 November 2021

(c) The Author(s), under exclusive licence to Springer Science+Business Media, LLC, part of Springer Nature 2021

\begin{abstract}
The COVID-19 pandemic outbreak has erupted corruption challenges across polities including Ghana. This situation has spurred anecdotal narratives underscoring a decline in citizens' trust, transparency perceptions, satisfaction and participation in pandemic activism, and thus catapulted civil society discourses into prominence. Therefore, we investigate civil society imperativeness to trust, transparency, satisfaction and participation, whilst mitigating corruption. Results $(n=375)$ of structural equation modeling revealed the negative impact of corruption on trust, satisfaction and transparency. Whereas, trust and transparency were revealed to be significant to satisfaction and participation, the civil society's efficacy was confirmed. Based on these, research and policy implications are proffered.
\end{abstract}

Keywords Corruption · COVID-19 · Citizens and government · Civil society participation · Ghana

Vincent Ekow Arkorful saintvincentino@gmail.com

Nurudeen Abdul-Rahaman nurudeenkuberke@gmail.com

Hidaya Sungjun Ibrahim shidayaibrahim@gmail.com

Vincent Ansah Arkorful vincentansaha@gmail.com

1 Department of Government and International Studies, Hong Baptist University, Kowloon Tong, Kowloon, Hong Kong, China

2 Doctoral School of Education, The National Research University, Higher School of Economics, Moscow, Russia

3 Faculty of Education Studies, University of Education, Winneba, Ghana

4 Department of Geography and Rural Development, Kwame Nkrumah University of Science and Technology, Kumasi, Ghana 


\section{Introduction}

The outbreak of the novel COVID-19 has unleashed negative consequences on national economies and households alike. The urgency of the situation as amplified in mortality and morbidity cases has consequently informed the inception of resultsoriented mechanisms targeted at mitigating burdens and challenges imposed thereof. Significantly, much as these efforts have seen to ensuring affordable health care and access whiles procuring personal protective equipment and enhancing contact tracing, the deployment of other relevant control mechanisms have simultaneously given rise to irregularities like corruption (Nemexis, 2020; Bellows, 2020; Slattery \& Brito, 2020; Gascon Barbera 2020; Sishi \& Winning, 2020; Harris et al., 2020; Bradley et al., 2020; Maswood, 2020; Africa Research Bulletin, 2020; Rose-Ackerman, 2021). This situation is not unique to what pertains to the Ghanaian situation where pandemic-related corruption cases have been reported. Evidence to this is captured in the Community Development Alliance Corruption Risk Assessment Report raising issues of corruption ranging from vaccine theft to procurement arrangements made in contravention to Ghana's procurement Act. According to reports, such irregularities have culminated in the loss of whopping sums amounting to US\$ 1256 (Ghana News Agency, 2021, April, 16; Xinhua, 2021, March, 21).

Because this has been the case, social commentary has recently been inundated with widespread reports of citizens' decline in transparency perceptions, trust, satisfaction and overall, their participation intent regarding covid related activities. The urgency to countervail the situation has among other things led to citizens' proffering of a wide range of suggestions, high ranking among which include the entrenchment of the civil society's role as a capable force to help overcome the situation. The argument in this regard has to a larger extent revolved around the harnessable potentials of the civil society as a supportive structure that creates social capital from across social structures for social development and cohesion. In addition to this, the discourse has projected the civil society as a mirror that reflects the amalgam of an entire social structure. In light of these views, advocates underscore the civil society as potent to pull state and other relevant stakeholders together towards advancing social welfare.

This situation has conventionally provided the "smoking gun" to verify the relevance of the civil society in forging trust, satisfaction, transparency, participation in pandemic governance amidst corruption (Park \& Blenkinsopp, 2011; Beshi \& Kaur, 2020; Arkorful et al., 2021). Cognizant of the deleterious impacts of corruption on social systems and populations, there has been a groundswell of studies in recent times (Pathak et al., 2008; Park \& Blenkinsopp, 2011; Dahlberg \& Linde, 2016; Pellegata \& Memoli, 2018; Neshkova \& Kalesnikaite, 2019). Whereas prior governance-related studies have established the mediating and moderating imperativeness of trust (Park \& Blenkinsopp, 2011; Pathak et al., 2008), other seminal studies have probed and established the adverse correlations between corruption and satisfaction (Dahlberg et al., 2015; Pellegata \& Memoli, 2018).

Moreover, Neshkova and Kalesnikaite (2019) have also affirmed the impact of corruption on participatory governance. In a separate study, Zakaria (2013) 
also sheds light on the diminishing impact of corruption on civil society engagements. Against the backdrop of the relevance of trust and satisfaction (Pellegata \& Memoli, 2018; Neshkova \& Kalesnikaite, 2019), vis avis the deleterious effect of corruption on civil society, this study sets out to investigate the impact of corruption on trust, satisfaction and transparency. And particularly given the reports of corruption in Ghana, and the Ghanaian public's suggestion on the civil society's inclusion in COVID pandemic activities, our study does not only respond to such public discourse calls, but also finds it imperative to empirically probe the salience of the civil society in fostering trust, trust, satisfaction, transparency and satisfaction in pandemic governance amidst corruption. In light of the foregoing discussion, the current study broaches the civil society puzzle using the general systems theory as the theoretical underpinning for a quantitative study predicated on the structural equation modeling technique. This study contributes to literature by exploring the efficacy and efficiency of the civil society towards advancing participation. The remaining parts of the research is delineated as follows; "literature review" section discourses relevant related studies. Theories and hypotheses are captured under "theoretical background and research hypotheses". The "data and research method" section delineates approaches employed for the study. Data analysis and outcomes are spelt out under the "data analysis and results" section. Extensive elaboration of the study is captured under "discussion". The final section highlights "implications", "conclusion”, as well as "limitations and future research alternatives".

\section{Literature Review}

\section{Covid-19 Pandemic in Ghana}

Ghana recorded its first confirmed case of COVID-19 at the Noguchi Memorial Institute for Medical Research, on March 12, 2020. These were imported case from two people who had travelled from Norway and Turkey respectively. In the wake of the pandemic's outbreak, series of health protection measures and protocols have been incepted. These included the imposition of a three-week lockdown which started from March 20th, 2021 and ended on April, 20 th, 2021. This halted commercial activities. Excluding frontline workers composed of health workers and other indispensable public service providers like those belonging to the National Security Service, general activities were shut. Subsequently, the closure of both entry and exit boarder points affected travelling. Not ending there, the urgency of the pandemic situation brought into force the "Imposition of Restrictions Act, 2020 (IRA)”, pursuant to which an Executive Instrument (E.I. 64) was issued by the President of the Republic of Ghana. Also, in tandem with Section 169 of the Public Health Act of 2012 (Act 851), a public health emergency was declared (Addadzi-Koom, 2020). Further to these, the need to enhance tracking and contact tracing resulted in the development of a COVID-19 app on April 12 th, 2021. In addition to the enforcement of mask wearing and social distancing protocols, the formulation and subsequent implementation of these initiatives essentially helped 
in managing and containing the pandemic. Globally, as of 21/07/2021, there had been 191, 148, 056 confirmed covid cases including 4, 109, 3030 deaths, as well as 3, 568, 861, 733 vaccines administered (World Health Organization, 2021). Within the same period, Ghana had recorded 99, 734 cases with 817 deaths. Ghana received its first consignment of 600,000 doses of the AstraZeneca vaccine procured through the COVID-19 Vaccines Global Access Facility-a World Health Organization-led initiative, in partnership with the Coalition for Epidemic Preparedness Innovations and the Global Alliance for Vaccines and Immunizations (Gavi). As of 14/07/2021, 865,422 people had received the first doses of the covid vaccination. Another 405, 971 had received both first and second vaccination shots (Ghana Health Service, 2021). Amidst fighting the covid-19, there appears to be a wedge between the government of the Republic of Ghana and the civil society, a typical example of which is the back and forth between the Community Development Alliance (CDA) and the Minister for Information-Ursula Owusu-Ekuful-over a \$ 1 million dollar covid app contract impropriety as contained in the Covid-19 Corruption Risk Assessment report (Myjoyonline, 21 April, 2021). In this study precincts, part of the motivation to investigate the the civil society's in fighting the pandemic stems from occurrences of this nature.

\section{Ghana, COVID-19 and Corruption}

The canker of corruption is neither novel to developed nor developing countries. Nonetheless, the phenomenon's pervasiveness and its impact is widely witnessed in the latter. Despite the strong anti-corruption legal instruments in place, the existence of porous and weak institutions have provided a firm undergird for its thrive in polities of developing extractions. The general situation described above is nowhere different from what prevails in Ghana (a model and a bastion - in terms of democratic governance experimentation in Africa) where the canker has substantially affected social, economic, political and cultural developments (Yeboah-Assiamah \& AlesuDordzi, 2016; Kasser-Tee, 2020). In the case of Ghana, the unwavering national commitment to fighting corruption and ensuring transparency and accountability in governance has resulted in the creation of statutory outfits such as the Office of the; Attorney General (AG), Auditor General, Public Accounts Committee of Parliament, Economic and Organized Crimes Office (EOCO), Commission for Human Rights and Administrative Justice (CHRAJ) and more recently, that of the Special Prosecutor (SP) among others. Taken together these arrangements, it is not surprising that Ghana has over the years ranked high in corruption scores indexed by Transparency International.

These arrangements notwithstanding, Ghana's public sector has for some time now been a citadel of corruption (Owusu et al., 2021). Sensitive sectors including the public health have since the outbreak of the novel coronavirus experienced cases of corruption and irregularities. This is evidenced in the Community Development Alliance's (CDA) Corruption Risk Assessment Report highlighting among others, the 36 Covishield vaccine (each worth US\$ 34.9) theft involving health sector workers (Ghana News Agency, 2021, April, 16; Xinhua, 2021, March, 21). In this vein 
comes report of improrpiety regarding the award of a million dollar covid-tracker app development contract to foreign entities (i.e., iQuent technology and Ascend Digital solutions) unregistered with the Ghana Procurement Authorities (GPA), therefore implying contract award without recourse to Ghana's tender and procurement processes. Furthermore, the COVID-19 Transparency Accountability Project (CTAP) - a pan African initiative incepted to deepen transparency and accountability in public expenditure, also reports disquieting cases of COVID-19 corruption and related procurement irregularities. Precisely, the report projects a dearth of clarity, delay in accounting and auditing among others (Myjoyonline, 28 January, 2021; Myjoyonline, 16 April, 2021; Myjoyonline, 22 April, 2021; Myjoyonline, 9 July, 2021; Myjoyonline, 12 June 2021). The rife issue of corruption is also highlighted by the Community Development Alliance (CDA) and the Commonwealth Foundation report christened; Strengthening Covid-19 Accountability Mechanisms (SCAM) (Ghanaweb, 2021, May 12). Weaving together these strands of corruption reports in Ghana-a country touted exemplary in corruption indices - raises worry than comfort, hence the study's preoccupation to explore corruption and citizens' participation.

\section{Theoretical Background and Research Hypotheses}

In view of the study's intention to investigate corruption impacts and possible countervailing alternatives, this study engages the general systems theory as the theoretical lens. Underlying the theory is the concept of social structures as composed of complex grids of interdependent and interacting elements. Differently conceptualized, the general systems theory portrays a corporate network of individuals embedded in different types of structures (i.e., formal, semi-formal, informal). Extrapolating these generalization strands within our study presupposes society as a system that draws resources (i.e., financial, human etc.) from its immediate or remote surroundings, for onward reinvestment into mainstream systems (Kindyamtima, 2017). As a management paradigm, the theory does not only delineate systems as composed of boundaries (i.e., sub and supra systems), but also, entreats actors within systems to acknowledge the complementary roles played by other actors in each of the systems, and their respective boundaries (Hannagan, 2002). The imperative role of the boundaries lie in its potency to filter system inputs from outputs (Oyebade, 2001). For this reason, it is important that concerted endeavors towards interrogating systems take into cognizance inherent interrelationships and their collective interaction with the environment within which they are embedded. Overarching to the system theory is the perception of system dependency on the environment. To this end, given corporate social structures as open systems underscore their dependence on, and influence by the external environment - which largely determines their functionality. In relation to the pandemic, the roll out of responsive policy framework is apparently in reaction to an alteration in the environment and/or society. With a myriad of actors initiating efforts (i.e., input) and influencing the decision making process (i.e., processing and output), Plomp and Pelgrum (1993) acknowledge system inherent diversities and describe them as entailing subsystems at macro (i.e., 
national), meso (i.e., regional) and micro (i.e., institutional, organizational etc.) levels. Considering systems as a whole makes it understandable that the absence or malfunction of a constituent part may invariably exerts a toll on the entire system functionality. Against the backdrop of the foregoing generalization of systems, this study conceptualizes the effort towards fighting the pandemic as a system machinery which requires a multipronged stakeholder approach. With this as a premise, the current study probes the significance of civil society participation in forging trust, transparency, satisfaction and citizens' participation whilst mitigating the impacts of corruption. Proceeding on this tangent, the study relies on Hanson's input-processoutput-feedback model (Oyebade, 2001) and considers the civil society and their participation as indispensable to social development and/or reconstruction, and the overall fight against the pandemic. Moreover, relying on the theory's proposition of system dependence on the external environment (via relationship networks) and structures within, this study seeks to test the validity of the theory by verifying the imperativeness of the civil society in augmenting trust, satisfaction, transparency and population wide participation. In this regard, the current study finds it important to clarify that, the profundity of the theory's deployment in this study is steeped in unravelling the extent and depth of civil society participation to informing satisfactory governance outcomes.

\section{Hypotheses Development}

\section{Corruption, Trust and Satisfaction}

Trust has been established as an essential ingredient in global corporate governance spheres. From a broad and narrow perspective, trust has been used in reference to the individual's perceptions regarding system effectiveness and efficiency. Differently conceptualized, trust is largely hinged on the individual's views pertaining to a particular system's responsiveness, openness and efficacy in dispensing resultoriented outcomes (Liang et al., 2018; Pellegata \& Memoli, 2018). Within governance study contexts, studies have endeavored probing and establishing the detrimental impacts of corruption on governance (Anderson \& Tverdova, 2003; Chang \& Chu, 2006). On this premise, pervasive corruption is noted to trigger legitimacy crises and abuse of power whilst fomenting widespread populationwide discontent (Doig \& Theobald, 2000). In addition to this, much as these studies underscore the impact of corruption on citizens' trust and satisfaction levels, they also distinguish the seminal imperativeness of trust and satisfaction to corporate governance dividends (Pellegata \& Memoli, 2018; Liang et al., 2018; Arkorful et al., 2021). Conversely, other erstwhile studies on corruption have underscored its inherent advantages to include its potency to break open labyrinthine processes and procedures characterizing bureaucracies (Aidt, 2003; Grosjean, 2011; Holmes, 2006; Levy, 2007). Ratiocinating the foregoing discourse project an exegesis pointing to the sparse and varying context-specific impacts of corruption. In this vein, it is interesting to note that, in the wake of the covid-19 pandemic outbreak and its lethal consequences such as erupting corruption, scholarship till now remains reticent 
on proving its effects on citizens' trust, satisfaction and participation. Against the backdrop of this observation, the current study sets out to explore these relationships and thus propose the hypotheses below:

H1. Corruption has a negative relationship with trust.

H2. Corruption has a negative relationship with transparency.

H3. Corruption has a negative relationship with satisfaction.

\section{Trust, Transparency, Satisfaction}

Trust, transparency and satisfaction are essential linchpins to corporate governance. Their relevance to governance is partly ingrained in how they contribute to building a social capital stronghold base for governance-centred undertakings and its related engagements. Conceptualized as an amorphous variant, trust has attracted a panoply of conceptualizations in scholarship. In the views of Arkorful et al. (2021), trust entails the degree of confidence and belief reposed in a system by the individual. Thomas (1998) on the other hand seem to agree with the notion of trust as predicated on a set of held beliefs rather than expectation (Thomas, 1998). Tschannen-Moran and Hoy (2000) and Beshi and Kaur (2020) collectively conceptualize trust as revolving around individual's willingness to invest confidence in a trustee-in anticipation for positive outcomes. Based on these elucidations, it is instructive to point out that, trust does not erupt in a vacuum; rather it is preconditioned on positive feedback bordering on a trustee's tried, tested and proven capability to efficiently and effectively discharge on statutory obligations and mandates. Most importantly, the consolidation of trust helps in erecting a social capital that dovetails into shaping, reshaping and determining truster-trustee relationship within corporate social structures.

Largely, trust generated is enhanced, augmented and sustained by a plethora of factors including, but limited to transparency, which constitutes an indispensable element in as far as good stakeholder relationship in corporate governance is concerned (Redford, 1969). Talking about transparency, it refers to the degree of openness in governance. Arkorful et al. (2021) trace the emergence of transparency to the 1980's World Bank pursuit of institutional reforms in developing countries. This was in essence meant to engineer innovative pathways to effective and efficient pro participatory governance measures, whilst sustaining inroads therein. Therefore, it occasions no surprise that government stakeholders are exerting efforts to inject an appreciable dosage of trust and transparency in governance to promote satisfaction. These efforts notwithstanding, the outbreak of the covid-19 pandemic appears to have created opportunities for the resurgence of corruption, especially in a developing country like Ghana where there currently abound reports of corruption causing a substantial decline in not only citizens' satisfaction, but also, their trust, transparency levels. Considering these anecdotal reports, and cognizant of prior study findings establishing the imperativeness of trust, transparency and satisfaction to governance, this study sets out to explore the relationships, and furthermore, establish 
their veracity in relations to covid-19 management. On this score, our study proposes the following hypotheses:

H4. Trust has a significant positive relationship with satisfaction.

H5. Transparency has a significant positive relationship with satisfaction.

\section{Trust, Satisfaction, Transparency and Participation}

Further to the above discourse, the consolidation of trust, satisfaction and transparency is gravid with the potential to enhance participation. In a seminal study on decentralization and participatory governance in Ghana, the findings of Arkorful et al. (2020a) confirms the salience of transparency and trust to local citizens' participation in local state administration. In this study, in addition to trust and transparency, we introduce satisfaction as a mediating variable to test their collective effects as antecedents to participation in covid-19 activities. Drawing motivation from Arkorful et al. (2021) the study sets out to test the salience of trust, satisfaction, transparency and participation and thus propose the hypotheses below:

H6. Satisfaction has a significant positive relationship with participation.

H7. Trust has a significant positive relationship with participation.

H8. Transparency has a significant positive relationship with participation.

\section{Moderating Role of Civil Society Participation}

In democracies where there exist germane spaces for participatory governance, the civil society is recognized as a distinct indispensable state arm with the potential to act as a control valve, efficiently regulating government and its ancillary stakeholders' exercise of powers and functions. In essence, the exercise of these checks and balances are essential to purging governance of its chronic ailments. Specifically, the civil society has played various roles across various societies around the world. In Ghana for instance, the civil society has played key roles towards democratic experimentation and consolidation (Botchway, 2018). In light of this, the civil society could be appreciated as a conveyor belt for advancing growth, stability and general development. Growing streams of studies report mixed outcomes on civil society. Whiles Botchway, (2018) highlights the civil society's positive potentials, others like Chambers and Kopstein (2001) lay bare its negative tendencies. These mixed findings notwithstanding, other erstwhile studies have also discoursed on the potential factors that could diminish the socio-political space for the civil society's role in participatory governance (Richardson, 2012; Zakaria, 2013). Cardinal amongst these include corruption (Kostadinova \& Kmetty, 2019; Neshkova \& Kalesnikaite, 2019). Taking note of the mixed reports regarding civil society's salience, the current study takes a divergent turn to probe its role in enhancing transparency, trust, satisfaction and participation relative to the COVID-19 pandemic. In the Ghanaian context, the civil society's role in steering the peaceful transition from military adventurism 
(in the 1980's) to a democracy (in the 1990's) has earned it an enviable position. However with the advent of multiparty democracy, the civil society space appears bifurcated along partisan lines. This situation has created an unappealing perception of the civil society as an amalgam of self-interest seekers carrying out the bidding of their sponsors. Ostensibly, this situation presents a difficulty for governance in terms of harnessing civil society potentials. Given the outbreak of the pandemic, the eruption of corruption and the mixed perceptions of the civil society, all against the civil society's hazy image in Ghana, as part of attempts to test civil society's role, the research employs it as a moderating construct to propose the following hypotheses;

H9. Civil society participation has a significant moderating influence on the relationship between trust and participation.

H10. Civil society participation has a significant moderating influence on the relationship between transparency and participation.

\section{Data and Research Method}

\section{Study Settings, Sample and Data Collection}

Considering the need to draw a representative sample to help strengthen the study findings, the cross-sectional study approach was utilized to draw data from 1/5/2021 to $31 / 07 / 2021$. And given Ghana as a big country composed of sixteen administrative regions, the capital city of Accra was selected for this study. Refer to Fig. 3. The selection of the study setting was done with recourse to its heterogeneous and cosmopolitan composition (Arkorful et al., 2021).

By adhering to the recommendations of Songsore (2003) and Agyei-Mensah and Owusu (2010), the study area was segmented into low, middle and high income areas. Whereas the low income areas are typified by poor road networks, congestion and social service deficits, the middle income areas on the other hand are characterized by less congestion and social service access constraints. The high income areas, largely uncongested, are better off than the low and middle income areas in terms of access to social services and overall standard of living. In sampling participants, the simple random sampling technique was used. Importantly, this technique helped in selecting participants with characteristics cutting across gender, age, education and residence demographic divides. Further to this, the study sample was determined according to the recommendations of Hair et al., (2010) and Kline (2010) who proffer a sample range of 200-300 as appropriate and suitable for SEM-based studies. The researchers however increased the sample size. To this end, the study printed and administered 390 questionnaires. At the end of data collection, 385 questionnaires were retrieved. This constituted a 99 percent response rate. Table 1 presents the demographic details of study participants.

Nonetheless, after sorting questionnaires with unfinished responses, there remained 375 questionnaires. A structured questionnaire with closed ended 
Table 1 Demographic characteristics of respondents

\begin{tabular}{llc}
\hline & Frequency & Percent \\
\hline Gender & & \\
Female & 171 & 45.6 \\
Male & 204 & 54.4 \\
Age & & \\
$18-25$ & 92 & 24.5 \\
$26-35$ & 97 & 25.9 \\
$36-45$ & 73 & 19.5 \\
$46-55$ & 89 & 23.7 \\
Above 55 & 24 & 6.4 \\
Educational level & & \\
High school & 37 & 9.9 \\
Diploma & 62 & 16.5 \\
Bachelor & 108 & 28.8 \\
Master & 94 & 25.1 \\
Doctorate & 54 & 14.4 \\
Others & 20 & 5.3 \\
Residence & & \\
Rural & 97 & 25.9 \\
Peri-urban & 146 & 38.9 \\
Urban & 132 & 35.2 \\
\hline & &
\end{tabular}

questions was used in this study. Cognizant of mono methodological studies' vulnerability to research bias, the current research conducted common method bias test, and the results revealed no threat (Harman, 1976; Zhu et al., 2013).

\section{Scale Development and Pretesting}

Prior to data collection, the study instrument was piloted. Piloting was conducted with the rationale to help restructure and clarify its validity and reliability within the study context. It is important to reiterate that, piloting helped in restructuring and rewording the questionnaire, and thus, augment its comprehension to study participants. Two rounds of piloting were conducted with two groups composed of academics and practitioners with governance relationships. A mixed approach entailing focus group discussions and questionnaire interview were used during piloting. In all these, feedback gathered were channeled into improving the questionnaire which was finally approved by the groups of academics and practitioners. Afterwards, data collection began. 


\section{Development of Construct Measurement}

Central to the study's objective to establish relationships between constructs and their respective items, a six construct theoretical framework was proposed for this research. Constructs and their items were adapted from erstwhile studies which had prior employed and established their validity and reliability. A five-point Likert scale starting from "strongly disagree" to "strongly agree" was used in measuring these items. Precisely, items for measuring "satisfaction" and "corruption" were measured with four items adapted from Park and Blenkinsopp (2011). Moreover, items for "trust" (3 items), "civil society participation" (3 items), and "transparency" (4 items) were all adapted from Arkorful et al. (2021). Finally, participation was measured with four items adapted from Arkorful et al. (2021). Overall, these items were restructured to suit the study context. The list of constructs and their corresponding items are presented under "Appendix".

\section{Data Analysis and Results}

The structural equation modelling technique was used for data analysis in this study. The use of this technique was based on not only the quantitative nature of the study, but also, the proximate reason to verify and delineate relationships between proposed study constructs (Fig. 1). The use of the SEM approach in quantitative studies has the following advantages: $(i)$ verifying a concatenation of direct and indirect relationships within a model simultaneously; (ii) establishing latent and observable variable relationships; (iii) using multiple indicators to test construct level hypotheses whilst capturing measurement variables by delimiting observed random errors

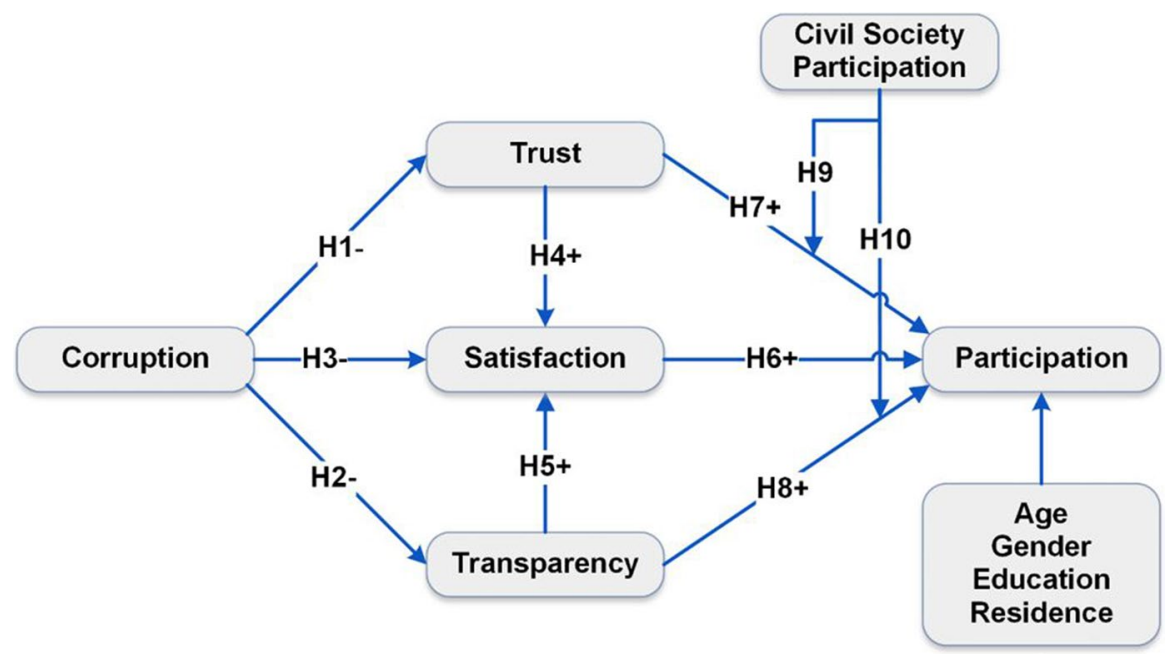

Fig. 1 Proposed conceptual framework 
Table 2 KMO and Bartlett's Test

\begin{tabular}{lll}
\hline $\begin{array}{l}\text { Kaiser-Meyer-Olkin (KMO) Measure of Sampling } \\
\text { Adequacy }\end{array}$ & .856 \\
\hline Bartlett's Test of Sphericity & Approx. Chi- & 4195.332 \\
& Square & \\
& df & 231 \\
& Sig & .000 \\
\hline
\end{tabular}

Table 3 Factor loadings and cross-loadings

\begin{tabular}{llllllll}
\hline Construct & Items & SAT & PAT & TRA & COR & SC & TRU \\
\hline Satisfaction (SAT) & SAT1 & $\mathbf{. 8 7 1}$ & .019 & -.025 & .026 & -.044 & .020 \\
& SAT2 & $\mathbf{. 8 9 2}$ & .053 & -.028 & .025 & -.022 & .000 \\
& SAT3 & $\mathbf{. 9 2 6}$ & -.018 & -.016 & -.039 & .027 & -.022 \\
& SAT4 & $\mathbf{. 8 8 2}$ & .004 & .045 & .011 & .015 & -.003 \\
Participation (PAT) & PAT1 & .050 & $\mathbf{. 7 0 6}$ & .099 & .039 & .002 & .043 \\
& PAT2 & -.022 & $\mathbf{. 9 2 4}$ & -.033 & -.043 & -.040 & .000 \\
& PAT3 & -.015 & $\mathbf{. 8 2 1}$ & .004 & -.014 & .048 & .039 \\
Transparency (TRA) & PAT4 & .055 & $\mathbf{. 8 2 4}$ & -.009 & .015 & .014 & -.045 \\
& TRA1 & .005 & .100 & $\mathbf{. 7 1 6}$ & -.095 & -.004 & .010 \\
& TRA2 & .007 & -.080 & $\mathbf{. 7 5 4}$ & .001 & .040 & .128 \\
Corruption (COR) & TRA3 & .014 & -.020 & $\mathbf{. 9 0 2}$ & .091 & -.042 & -.032 \\
& TRA4 & -.050 & .059 & $\mathbf{. 9 0 2}$ & -.013 & .006 & -.073 \\
& COR1 & -.131 & .027 & .063 & $\mathbf{. 7 0 7}$ & -.029 & -.081 \\
& COR2 & .133 & -.039 & -.003 & $\mathbf{. 8 1 1}$ & .070 & .031 \\
Civil Society Participation (CSP) & COR3 & -.066 & -.003 & -.063 & $\mathbf{. 8 0 9}$ & -.017 & .148 \\
& COR4 & .040 & .013 & .030 & $\mathbf{. 8 3 7}$ & -.015 & -.096 \\
& CSP1 & -.049 & .105 & -.097 & .045 & $\mathbf{. 8 5 0}$ & -.016 \\
& CSP2 & .054 & -.115 & .136 & -.015 & $\mathbf{. 8 0 1}$ & .013 \\
& CSP3 & -.026 & .024 & -.035 & -.010 & $\mathbf{. 8 9 4}$ & -.010 \\
Trust (TRU) & TRU1 & .051 & -.059 & .020 & .049 & .008 & $\mathbf{. 8 3 4}$ \\
& TRU2 & -.092 & .130 & -.053 & .050 & -.041 & $\mathbf{. 8 7 5}$ \\
& TRU3 & .054 & -.052 & .063 & -.106 & .027 &. $\mathbf{7 5 2}$ \\
\hline & & & & & & &
\end{tabular}

(Hair et al., 2010; Arkorful, 2022; Arkorful, Lugu and Shuliang, 2021; Arkorful et al., 2020a; Jianxun et al., 2021). The conduct of the SEM analysis was done by considering the two-step approach made up of the measurement and structural model. At the first step, the measurement model was used to ascertain relationships between variables and their items. At the second step, inter-construct level relationships were established using the structural model. Data analysis was carried out using Analysis of Moment of Structures (AMOS) complemented with the Statistical Package for Social Scientists software version 25. 


\section{Measurement Model Analysis}

The Statistical Package for Social Scientist version 25 was used for conducting exploratory factor analysis. Prior to this, KMO and Bartlett's Test was conducted. This revealed values confirming their adequacy with standard benchmarks (Table 2). Proceeding in this direction, values of factor loadings greater than 0.5 were subsequently examined. This test confirmed scores reconcilable with standard proposed values, which affirms the suitability and appropriateness of the model. On this score, outcomes ranged between 0.850 and 0.871 (Table 3). The confirmation of validity and reliability was established using the confirmatory factor analysis. On this threshold, initial purification of items was carried out using factor analysis. This revealed factor loadings to be greater than the conventional threshold of 0.7 , which makes it acceptable to proceed with structural equation modeling analysis. Furthermore, the principal component analysis was also carried out to interrogate all items employed in this research. After conducting the test of reliability, Cronbach alpha scores were revealed to be beyond 0.7 , therefore indicating a suitable convergent validity (Table 4). Average variance extracted (AVE) scores were further delimited by employing AVE as well as composite reliability (CR) scores. Scores confirmed values greater than 0.7 , thereby demonstrating a sufficient representation and reliability of constructs and their proposed items (Arkorful et al., 2020b, 2021. Scores of AVE were greater than 0.5 which demonstrates appropriate convergent validity for the study instrument (Fornell \& Larcker, 1981; Arkorful \& Lugu, 2021). AVE scores are utilized to illuminate verified discriminant validity outcomes which do not reconcile with a measure from which it is supposed to be unique. Table 4 captures scores of AVE square roots greater than inter-construct correlations. This signifies an appropriate convergent validity.

\section{Measurement and Structural Model Evaluation}

Afterwards, the study proceeded to verify the measurement and structural model. The overarching focus here was on evaluating the goodness of fit of the model, and the various significant paths of the hypotheses put forward in the proposed model

Table 4 Mean, standard deviation, validity and correlation

\begin{tabular}{|c|c|c|c|c|c|c|c|c|c|c|c|}
\hline Construct & Mean & SD & $\mathrm{CA}$ & $\mathrm{CR}$ & AVE & PAT & SAT & TRU & TRA & COR & CSP \\
\hline PAT & 2.816 & .752 & .858 & .865 & .617 & .786 & & & & & \\
\hline SAT & 2.315 & .824 & .915 & .918 & .737 & $.444 * * *$ & .858 & & & & \\
\hline TRU & 2.732 & .850 & .778 & .778 & .539 & $.454 * * *$ & $.492 * * *$ & .734 & & & \\
\hline TRA & 3.374 & .780 & .848 & .852 & .593 & $.438 * * *$ & $.333^{* * *}$ & $.378 * * *$ & .770 & & \\
\hline COR & 2.514 & .709 & .797 & .806 & .513 & $-.356^{* * *}$ & $-.440 * * *$ & $-.511 * * *$ & $-.266 * * *$ & .716 & \\
\hline CSP & 3.634 & .993 & & .812 & .595 & .000 & .073 & .054 & -.025 & -.057 & .771 \\
\hline
\end{tabular}

*** $p<.001, \mathrm{SD}=$ Standard deviation, $\mathrm{CA}=$ Cronbach Alpha, $\mathrm{CR}=$ Composite Reliability, AVE $=$ Average variance extracted 
Table 5 Model fit measures

\begin{tabular}{lllll}
\hline Measurements & Indices & Criterion & \multicolumn{2}{l}{ Results } \\
\cline { 4 - 5 } & & & Structural model & Measurement \\
\hline Absolute fit measures & AGFI & $>.80$ & .898 & .898 \\
& GFI & $>.90$ & .918 & .922 \\
Incremental fit measures & RMSEA & $<.08$ & .039 & .046 \\
& NFI & $>.90$ & .902 & .919 \\
& CFI & $>.90$ & .962 & .962 \\
& IFI & $>.90$ & .962 & .962 \\
& CMIN/DF & $<3.00$ & 1.560 & 1.792 \\
\hline
\end{tabular}

Table 6 HTMT analysis

\begin{tabular}{lllllll}
\hline Construct & PAT & SAT & TRU & TRA & COR & CSP \\
\hline PAT & & & & & & \\
SAT & 0.482 & & & & & \\
TRU & 0.477 & 0.496 & & & & \\
TRA & 0.484 & 0.362 & 0.410 & & & \\
COR & 0.369 & 0.446 & 0.495 & 0.306 & & \\
CSP & 0.020 & 0.079 & 0.064 & 0.001 & 0.053 & \\
\hline
\end{tabular}

(Fig. 1). The gamut of dimensions cross checked for overall model fitness include: the normed fit index, the comparative fit index, the degree of freedom, the parsimonious comparative fit index and the root-mean-square error of approximation (Table 5). Data analysis revealed fitness scores in tandem with the proposed criterion (Arkorful \& Lugu, 2021; Arkorful et al., 2021; Jianxun et al., 2021). This testifies to the acceptability and appropriateness of the study's measurement and structural model. Further, discriminant validity test was carried out using the Heterotrait-Monotrait criterion, which requires values less than 0.850 (Kline, 2010) or 0.90 (Henseler et al., 2015). Results captured under Table 6 confirm that, our study outcome is in congruity with the required thresholds.

\section{Hypothesis Testing}

The test of the measurement and structural model was followed by hypotheses testing. Results of path analysis (Fig. 2) reveals a negative relationship between corruption and trust on one breadth, and between corruption and transparency on the other. This confirms our proposed hypotheses 1 and 2. Along the same tangent, corruption was confirmed to be negatively related to satisfaction, thereby confirming hypothesis 3. Furthermore, the significant positive relationship between trust and satisfaction is affirmed, which supports hypothesis 4 . In line with proposed hypothesis 5 , trust and satisfaction were empirically proven to be positively related. In tandem 


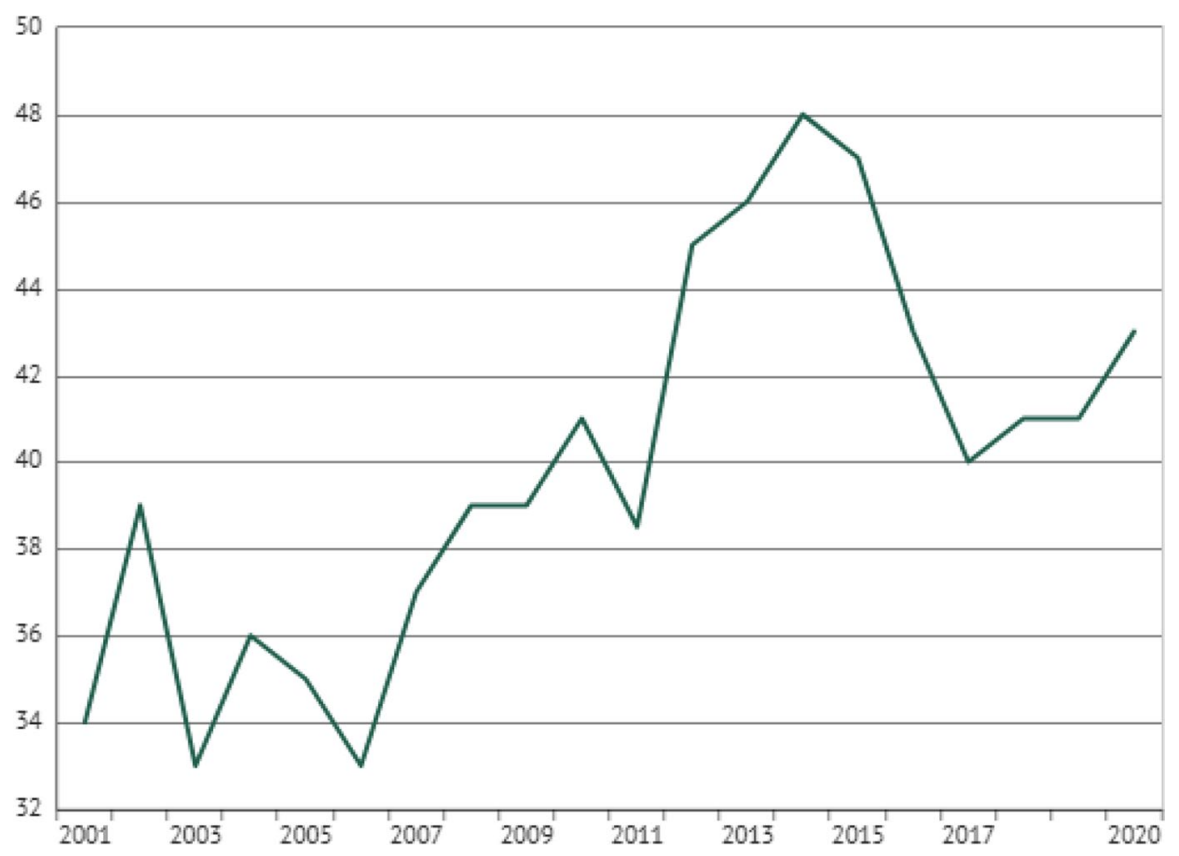

Fig. 2 Graph capturing Ghana's performance on the corruption perception index. Source: Computed by author using data from Transparency International

Table 7 Regression weight and hypothesis testing

\begin{tabular}{lllllll}
\hline Path & Estimate & Standard error & T value & P value & Hypothesis & Supported? \\
\hline $\mathrm{COR} \rightarrow$ TRU & -.870 & .129 & -6.766 & $* * *$ & $\mathrm{H} 1$ & Yes \\
$\mathrm{COR} \rightarrow$ TRA & -.548 & .116 & -4.715 & $* * *$ & $\mathrm{H} 2$ & Yes \\
$\mathrm{TRU} \rightarrow$ SAT & .308 & .077 & 3.990 & $* * *$ & $\mathrm{H} 4$ & Yes \\
$\mathrm{TRA} \rightarrow$ SAT & .152 & .054 & 2.843 & $* *$ & $\mathrm{H} 5$ & Yes \\
$\mathrm{COR} \rightarrow$ SAT & -.447 & .129 & -3.460 & $* * *$ & $\mathrm{H} 3$ & Yes \\
$\mathrm{SAT} \rightarrow$ PAT & .228 & .049 & 4.683 & $* * *$ & $\mathrm{H} 6$ & Yes \\
$\mathrm{TRU} \rightarrow$ PAT & .181 & .053 & 3.435 & $* * *$ & $\mathrm{H} 7$ & Yes \\
TRA $\rightarrow$ PAT & .240 & .044 & 5.501 & $* * *$ & $\mathrm{H} 8$ & Yes \\
Age $\rightarrow$ PAT & -.024 & .023 & -1.030 & .303 & & \\
Gender $\rightarrow$ PAT & .157 & .059 & 2.659 & $* *$ & & \\
Education $\rightarrow$ PAT & .000 & .021 & .000 & 1.000 & & \\
Residence $\rightarrow$ PAT & -.019 & .036 & -.539 & .590 & & \\
\hline
\end{tabular}

${ }^{* * *} \mathrm{p}<.001, * * \mathrm{p}<.01$

with hypothesis 6, satisfaction was revealed to be significantly related to participation. In addition to these, trust and participation were shown to be significantly related. A similar positive relationship was confirmed for transparency and 
Table 8 Hierarchical regression analysis

\begin{tabular}{|c|c|c|c|c|c|}
\hline \multirow[t]{2}{*}{ Model } & \multirow[t]{2}{*}{ Construct } & \multicolumn{2}{|c|}{$\begin{array}{l}\text { Unstandardized coef- } \\
\text { ficients }\end{array}$} & \multirow[t]{2}{*}{$\mathrm{T}$ value } & \multirow[t]{2}{*}{ Significant } \\
\hline & & $\beta$ & Std. Error & & \\
\hline \multirow[t]{2}{*}{1} & Trust & .252 & .042 & 5.950 & .000 \\
\hline & Transparency & .306 & .046 & 6.622 & .000 \\
\hline \multirow[t]{3}{*}{2} & Trust & .252 & .042 & 5.929 & .000 \\
\hline & Transparency & .306 & .046 & 6.613 & .000 \\
\hline & Civil Society Participation & .003 & .034 & .079 & .937 \\
\hline \multirow[t]{5}{*}{3} & Trust & .575 & .160 & 3.595 & .000 \\
\hline & Transparency & -.224 & .175 & -1.281 & .201 \\
\hline & Civil Society Participation & -.255 & .154 & -1.654 & .099 \\
\hline & Trust $\times$ Civil Society Participation & -.087 & .042 & -2.094 & .037 \\
\hline & Transparency $\times$ Civil Society Participation & .147 & .047 & 3.130 & .002 \\
\hline
\end{tabular}

participation. These outcomes were in sync with our hypotheses 7 and Table 8 . Overall, all proposed hypotheses (Table 7) were supported.

\section{Test of Mediation}

Next, following the proposition of Hayes (2017), test of mediation effect was conducted with 5000 bootstrap samples. This was carried out at a $95 \%$ confidence interval, representing a 5\% margin of error. Test of mediation revealed that the relationship between corruption and participation was mediated by trust. Whereas results demonstrated the significant mediating role of transparency between corruption and participation, satisfaction was confirmed to moderate the relationship between corruption and participation. Moreover, trust and satisfaction were collectively affirmed to moderate the relationship between corruption and participation. Finally, empirical outcomes of mediation test demonstrated the collective moderating strength of

Table 9 Indirect effect analysis

\begin{tabular}{lllll}
\hline Path & Estimate & \multicolumn{2}{l}{$95 \%$ confidence interval } & \multirow{2}{*}{ Result } \\
\cline { 3 - 4 } & & Lower level & Upper level & \\
\hline $\mathrm{COR} \rightarrow \mathrm{TRU} \rightarrow$ PAT & -.068 & -.111 & -.034 & Significant \\
$\mathrm{COR} \rightarrow \mathrm{TRA} \rightarrow \mathrm{PAT}$ & -.094 & -.145 & -.051 & Significant \\
$\mathrm{COR} \rightarrow \mathrm{SAT} \rightarrow \mathrm{PAT}$ & -.150 & -.206 & -.100 & Significant \\
$\mathrm{COR} \rightarrow \mathrm{TRU} \rightarrow \mathrm{SAT} \rightarrow \mathrm{PAT}$ & -.039 & -.062 & -.021 & Significant \\
$\mathrm{COR} \rightarrow \mathrm{TRA} \rightarrow \mathrm{SAT} \rightarrow$ PAT & -.018 & -.032 & -.008 & Significant \\
\hline
\end{tabular}


transparency and satisfaction on the relationship between corruption and participation. The results of the mediation test are captured under Table 9.

\section{Test of Moderation}

Consequently, the research probed moderation at two levels. In this case, the study first tested how civil society participation as a moderating variable affects the relationship between trust and participation, and secondly, how civil society participation impacts the relationship between transparency and participation. Using SPSS software version 25, hierarchical regression was conducted. Hierarchical regression is cardinal to signifying interaction effects between variables. This analytical technique helps researchers enter variables chronologically in order of prominence (Cohen \& Cohen, 1983). Under Table 8, the study presents unstandardized regression results of interaction effects between the independent variables (trust and transparency) and civil society participation (moderating variable) (Fig. 3).

Under this circumstance, the independent variable is the variable whose relationship with the dependent variable is being moderated. The moderator on the other hand is the independent variable exerting the moderating effect. The final interaction is the moderation outcome. Results of moderation as captured under Fig. 4 and 5 indicate the significant moderation of civil society participation on the relationship

Fig. 3 Map of Ghana showing the study area. Note: Study area highlighted in pink

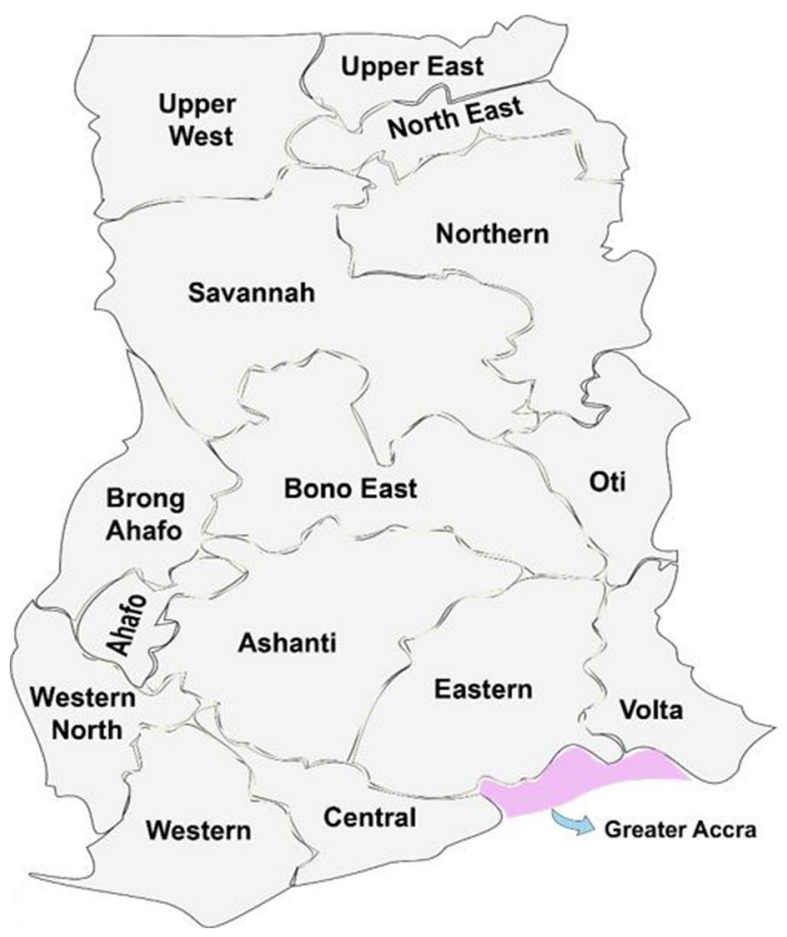




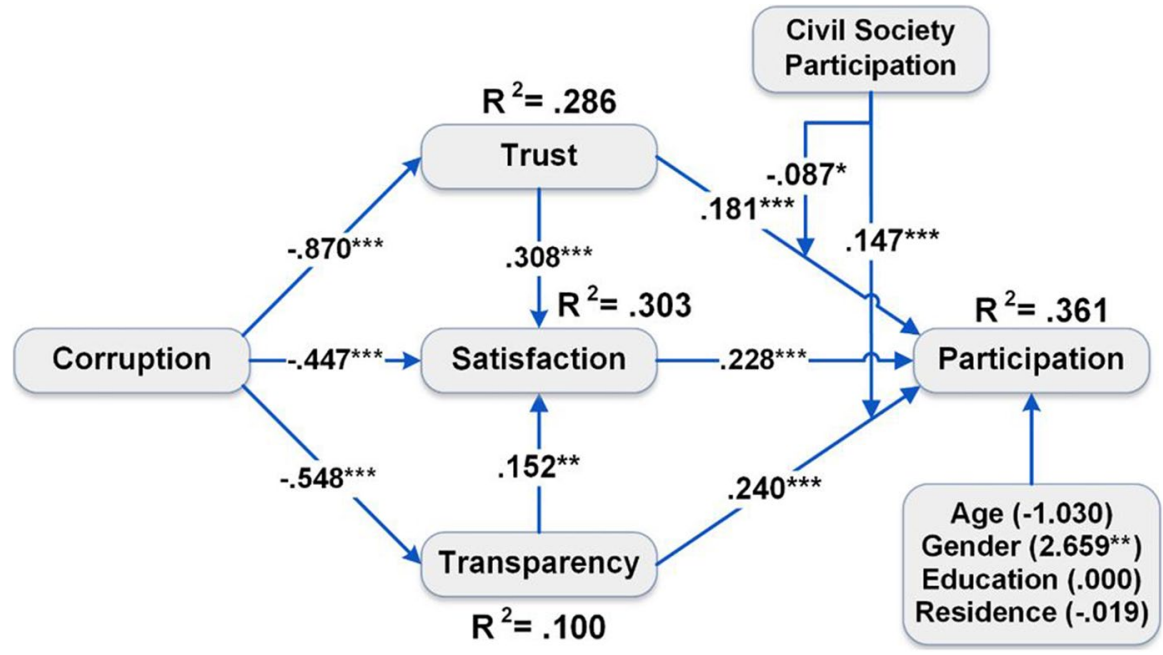

Fig. 4 Validated research model showing with structural equation model paths

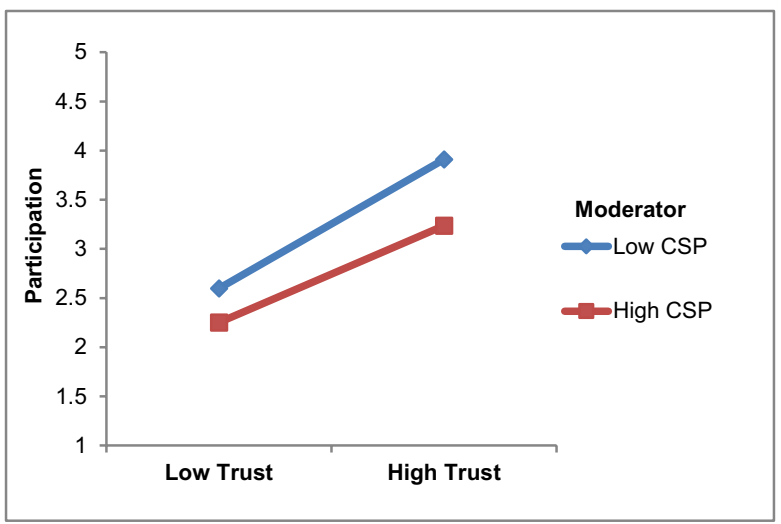

Fig. 5 Moderation results of relationship between trust and participation

between trust and participation, as well as transparency and participation. The results of moderation are summarized under Table 8.

\section{Discussion}

The reported cases of covid-afflicted corruption has ensuingly erupted a flurry of anecdotal narratives pointing to how the situation has culminated in a sudden decline in civil society participation, citizens' trust and transparency perceptions, satisfaction and participation. In response to this, the current study probes the impacts of corruption and the role of the civil society. Against the backdrop of the 
conceptualization of corporate administrative governance as an open system requiring a multistakeholder interaction at all levels (Kindyamtima, 2017), the study employs the general systems theory as the theoretical framework to investigate the relevance of the civil society to fostering transparency, trust, satisfaction and participation in COVID-19 management activism. The results of this study makes significant contributions to literature and stakeholders alike - on the potentials and possible roles of the civil society, relative to corporate pandemic governance (Table 9).

Empirical results of data analysis underscored the significant relationship between the constructs making up the proposed study framework. Specifically, results of data analysis affirmed a significant, but negative relationship between corruption, and trust, transparency and satisfaction. These outcomes were in congruence with hypotheses 1, 2 and 3. Our results are reconcilable with (Anderson \& Tverdova, 2003; Chang \& Chu, 2006; Justesen \& Bjornskov, 2014; Habibov $\&$ Cheung, 2016; Habibov, 2016). Taken together these results demonstrate how widespread corruption could sow seeds of distrust and dissatisfaction, as well as cause a decline in citizens' transparency perceptions. In view of these findings, much as it is a testimony to citizens' discontentment with corruption, it calls for stakeholders to try as much as possible to exert efforts targeted at offsetting governance deficits. To this end, good governance practices like transparency and accountability must be prioritized in covid management (Fig. 6).

Furthermore, consistent with hypotheses 4 and 5, whereas trust was revealed to have a significant positive relationship with satisfaction, the significant positive relationship between transparency and satisfaction received affirmation. Moreover, consistent with hypotheses 6, 7 and 8, the analysis of data underscored the positive relationship between satisfaction, trust and transparency, and participation. In addition to these findings, in agreement with hypotheses 9 and 10, results of data analysis established the significant moderating impact of civil society participation on the relationship between trust and participation on one hand, and transparency and participation on the other. These highlight the civil society as an entity gravid with potentials that could be harnessed to create, nurture, implement

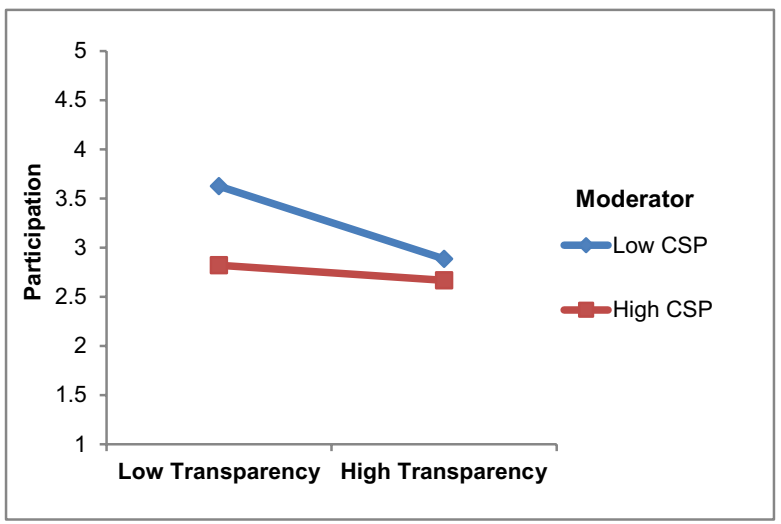

Fig. 6 Moderation results of relationship between transparency and participation 
and execute systems, institutions, as well as principles and values that disapproves impropriety and opacity. Though there exist variations in the degree of moderation, study results apparently corroborate the significance of the civil society as not only an anvil for beating and shaping governance outcomes, but also an enhancer of trust, transparency and satisfaction, the consolidation of which will finally help foster participation. The significant role of the civil society finds credence in Newton (2001) who emphasizes the salience of voluntary networks and groups to governance. For this reason, there is the need for government to redouble efforts and commitments towards creating an enhanced space that would guarantee engaging the civil society as development stakeholders. The already existence of community-based organizations, non-governmental organizations, chieftaincy institutions and other decentralised government and non-government bodies is sufficient to provide a wealth of social capital for civil society engagement in eschewing corruption, promoting citizens' trust, satisfaction, transparency and participation regarding the covid-19. The study went further to test the significance of the demographics (i.e., age, gender, education and residence), and the results of data analysis confirmed the significance of only gender.

\section{Implications}

This study confirms the adverse consequences of corruption on citizens' satisfaction, trust and transparency and overall, their participation in covid-19 activities. The study proceeds to provide empirical support for the salience of the civil society in corporate governance, precisely in pandemic management and governance. This suggest the implicit strength of the civil society to forging trust, satisfaction, transparency, and participation whilst curing chronic governance maladies like corruption. To this end, our study findings make it instructive for government to prioritize civil society engagement as very critical to fighting the covid-19 pandemic. Therefore, government must create sufficient space to this effect. Moreover, for purposes of capacity building, government must support civil society organizations with technical, human, fiscal and other forms of resources, which are critical to their effective and efficient delivery.

\section{Conclusion}

Using 375 sample drawn from a cosmopolitan setting-Accra, this study investigates civil society imperativeness to counterbalancing corruption whilst stimulating citizens' participation in covid activities. The general systems theory was employed as the theoretical framework, and our findings affirm the negative effects of corruption. Quite instructive and profound of our study outcome, in line with the postulation of the general systems theory emphasizing corporate systems effectiveness and efficiency as contingent on its holistic interaction with other system constituents, 
the current study confirms the civil society as significant to fighting the COVID-19. Juxtaposing our study findings against the systems theory's precincts makes obvious the indispensability of the civil society's participation in strengthening corporate governance and eliminating weaknesses like corruption.

\section{Limitations and Future Research Alternatives}

Though our study has strengths, like other research, it has limitations with significant research and policy bearings. This study utilized the quantitative approach. Considering the potency of qualitative studies in gathering extensive data, we recommend future studies to use either the qualitative or mixed method approaches. Study participants were sampled from a cosmopolitan setting. To explore the minute nuances in response across populations, we entreat future studies to be conducted in other areas in Ghana. However, these limitations do not invalidate the study findings.

\section{Appendix}

\begin{tabular}{|c|c|c|}
\hline Constructs & Items & Source(s) \\
\hline Satisfaction & $\begin{array}{l}\text { I will be satisfied when I trust pandemic } \\
\text { governance structures } \\
\text { I will be content when there is transparency } \\
\text { in pandemic governance } \\
\text { When I am satisfied with pandemic govern- } \\
\text { ance, I will participate in its activities } \\
\text { I am satisfied I will be confident in pandemic } \\
\text { governance stakeholders and their initia- } \\
\text { tives }\end{array}$ & Park and Blenkinsopp (2011) \\
\hline Participation & $\begin{array}{l}\text { When I am satisfied with pandemic govern- } \\
\text { ance, I will participate } \\
\text { I will not participate in pandemic governance } \\
\text { fraught with irregularities } \\
\text { Irregularities in pandemic management will } \\
\text { discourage me from participating } \\
\text { I will trust and participate in pandemic gov- } \\
\text { ernance activities when I am satisfied with } \\
\text { the level of transparency }\end{array}$ & Arkorful et al. (2021) \\
\hline
\end{tabular}




\begin{tabular}{|c|c|c|}
\hline Constructs & Items & Source(s) \\
\hline Transparency & $\begin{array}{l}\text { Clarity in pandemic governance elicits sup- } \\
\text { port from across stakeholder divide } \\
\text { Openness in pandemic governance engenders } \\
\text { a positive stakeholder perception } \\
\text { Transparency has the potential to arouse a } \\
\text { population wide contentment and confi- } \\
\text { dence for pandemic governance } \\
\text { Managing pandemic situations with openness } \\
\text { catalyzes stakeholder participation }\end{array}$ & Arkorful et al. (2021) \\
\hline Trust & $\begin{array}{l}\text { Stakeholder trust enhances a population wide } \\
\text { contentment with pandemic governance } \\
\text { Trust enhances stakeholder participation in } \\
\text { pandemic governance } \\
\text { Stakeholder trust augments pandemic govern- } \\
\text { ance initiatives }\end{array}$ & Arkorful et al. (2021) \\
\hline Corruption & $\begin{array}{l}\text { Corruption impairs pandemic management } \\
\text { and governance } \\
\text { Corruption breeds discontentment among } \\
\text { populations } \\
\text { Corruption weakens stakeholder relations } \\
\text { Corruption dampens positive perceptions } \\
\text { about stakeholder pandemic initiatives }\end{array}$ & Park and Blenkinsopp (2011) \\
\hline Civil society participation & $\begin{array}{l}\text { The civil society is capable of enhancing } \\
\text { pandemic governance outcomes } \\
\text { The civil society could be trusted to protect } \\
\text { national interest in pandemic management } \\
\text { The civil society has the capability to aug- } \\
\text { ment pandemic governance efforts }\end{array}$ & Arkorful et al. (2021) \\
\hline
\end{tabular}

\section{References}

Addadzi-Koom, M. E. (2020). Quasi-state of emergency: Assessing the constitutionality of Ghana's legislative response to Covid-19. The Theory and Practice of Legislation, 8(3), 311-327.

Africa Research Bulletin: Economic, Financial and Technical Series (2020) Africa: Corruption and Covid-19's Effect on Economies. 57(8) SN-0001-9852 https://doi.org/10.1111/j.1467-6346.2020. 09664.x.

Agyei-Mensah, S., \& Owusu, G. (2010). Segregated by neighbourhoods? A portrait of ethnic diversity in the neighbourhoods of the Accra Metropolitan Area, Ghana. Population, Space and Place, 16(6), 499-516.

Aidt, T. S. (2003). Economic analysis of corruption: A survey. The Economic Journal, 113(491), F632-F652.

Anderson, C. J., \& Tverdova, Y. V. (2003). Corruption, political allegiances, and attitudes toward government in contemporary democracies. American Journal of Political Science, 47(1), 91-109.

Arkorful \& Lugu (2021). Political Party "Footsoldierism" and "Vigilantism", An Empirical Study. In: Global Encyclopedia of Public Administration, Public Policy, and Governance, Springer Nature Switzerland. 
Arkorful, V. E., Hammond, A., Lugu, B. K., Basiru, I., Sunguh, K. K., \& Charmaine-Kwade, P. (2020a). Investigating the intention to use technology among medical students: An application of an extended model of the theory of planned behavior. Journal of Public Affairs, e2460.

Arkorful, V. E., Lugu, B. K., \& Shuliang, Z. (2021). Unearthing mask waste separation behavior in COVID-19 pandemic period: An empirical evidence from Ghana using an integrated theory of planned behavior and norm activation model. Current Psychology, 1-16.

Arkorful, V. E., Lugu, B. K., Hammond, A., \& Basiru, I. (2021, January). Decentralization and Citizens' Participation in Local Governance: Does Trust and Transparency Matter?-An Empirical Study. In Forum for development studies (pp. 1-25). Routledge.

Arkorful, V. E., Shuliang, Z., Muhideen, S., Basiru, I., \& Hammond, A. (2020). An empirical investigation of health practitioners' technology adoption: The mediating role of electronic health. International Journal of Public Administration, 43(12), 1013-1028.

Arkorful, V. E. (2022). Unravelling electricity theft whistleblowing antecedents using the theory of planned behavior and norm activation model. Energy Policy, 160, 112680.

Bellows, A. (2020, April 13). How global corruption threatens the US pandemic response. Carnegie endowment for international peace. https://carnegieendowment.org/2020/04/how-global-corruptionthreatens-u.s.-pandemic-response-pub- 81545

Beshi, T. D., \& Kaur, R. (2020). Public trust in local government: Explaining the role of good governance practices. Public Organization Review, 20(2), 337-350.

Botchway, T. P. (2018). Civil society and the consolidation of democracy in Ghana's fourth republic. Cogent Social Sciences, 4(1), 1452840.

Chambers, S., \& Kopstein, J. (2001). Bad civil society. Political Theory, 29(6), 837-865.

Chang, E. C., \& Chu, Y. H. (2006). Corruption and trust: Exceptionalism in Asian democracies? The Journal of Politics, 68(2), 259-271.

Cohen, J., \& Cohen, P. (1983). Applied multiple regression correlation analysis for the behavioral sciences (2nd ed.). Erlbaum.

Dahlberg, S., Linde, J., \& Holmberg, S. (2015). Democratic discontent in old and new democracies: Assessing the importance of democratic input and governmental output. Political Studies, 63, 18-37.

Doig, A., Theobald, R. (Ed.) (2000). Corruption and democratization. Frank Cass.

Fornell, C., \& Larcker, D. (1981). Evaluating structural equation models with unobservable variables and measurement errors. Journal of Marketing Research, 18(1), 39-50.

Ghana Health Service (2021) retrieved from: https://www.ghanahealthservice.org/covid19/ on 22/07/2021.

Ghana News Agency (2021, April 16).Covid-19 pandemic increases corruption risks in Ghana Report. Retrieved from: retrieved from https://www.myjoyonline.com/covid-19-pandemic-incre ases-corruption-risks-in-ghana-report/, on April 16, 2021.

Grosjean, P. (2011). The institutional legacy of the Ottoman Empire: Islamic rule and financial development in South Eastern Europe. Journal of Comparative Economics, 39(1), 1-16.

Habibov, N. (2016). Effect of corruption on healthcare satisfaction in post-soviet nations: A cross-country instrumental variable analysis of twelve countries. Social Science \& Medicine, 152, 119-124.

Habibov, N., \& Cheung, A. (2016). The impact of unofficial out-of-pocket payments on satisfaction with education in Post-Soviet countries. International Journal of Educational Development, 49, 70-79.

Hair, J. F., Black, W. C., Babin, B. J., \& Anderson, R. E. (2010). Multivariate data analysis (7th ed.). Pearson Prentice Hall.

Hannagan, T. (2002). Management: Concepts and practices. Prentice Hall.

Harman, H. H. (1976). Modern factor analysis. University of Chicago press.

Hayes, A. F. (2017). Introduction to mediation, moderation, and conditional process analysis: A regression-based approach. Guilford publications.

Henseler, J., Ringle, C. M., \& Sarstedt, M. (2015). A New Criterion for Assessing Discriminant Validity in Variance-based Structural Equation Modelling. Journal of the Academy of Marketing Science, 43(1), 115-135.

Holmes, L. (2006). Rotten States? Duke University Press.

Jianxun, C., Arkorful, V. E., \& Shuliang, Z. (2021). Electronic health records adoption: Do institutional pressures and organizational culture matter?. Technology in Society, 65, 101531.

Justesen, M. K., \& Bjørnskov, C. (2014). Exploiting the poor: Bureaucratic corruption and poverty in Africa. World Development, 58, 106-115. 
Kasser-Tee, C. (2020). The role of women in the fight against corruption in Ghana. Development in Practice, 31(4), 477-483.

Kindyamtima, E. M. (2017). Challenges Facing Schools Management on the Implementation of Free Education Reform in Tanzania: A Case of Dodoma Region (Doctoral dissertation, The Open University of Tanzania).

Kline, R. B. (2010). Principles and practice of structural equation modelling (3rd ed.). Guilford Press.

Kostadinova, T., \& Kmetty, Z. (2019). Corruption and political participation in Hungary: Testing models of civic engagement. East European Politics and Societies, 33(3), 555-578.

Levy, D. (2007). Price adjustment under the table: Evidence on efficiency-enhancing corruption. European Journal of Political Economy, 23(2), 423-447.

Liang, L. J., Choi, H. C., \& Joppe, M. (2018). Exploring the relationship between satisfaction, trust and switching intention, repurchase intention in the context of Airbnb. International Journal of Hospitality Management, 69, 41-48.

Maswood, M. H. (2020, July 13). No let-up in health sector corruption. Newage Bangladesh. https:// www.newagebd.net/article/111033/mo-let-up-in-health-sector-corruption

Myjoyonline. (21 April, 2021). Certify your Covid-19 Corruption Risk Assessment or we will use it as toilet paper - Ursula Owusu-Ekuful to CDA. Retrieved from: https:/www.myjoyonline.com/certify-yourcovid-19-corruption-risk-assessment-or-we-will-use-it-as-toilet-paper-ursula-owusu-ekuful-to-cda/.

Myjoyonline. (22 April, 2021). Covid-19 Corruption Risk Assessment: Every public contract must conform to transparency rule - CDA Director. Retrieved from: https://www.myjoyonline.com/covid-19corruption-risk-assessment-every-public-contract-must-conform-to-transparency-rule-cda-director/.

Myjoyonline.com. (12 June, 2021). People are using Covid-19 to engage in grand corruption - Kofi Bentil. Retrieved from: https://www.myjoyonline.com/people-are-using-covid-19-to-engage-in-grandcorruption-kofi-bentil/.

Myjoyonline.com (16 April, 2021). Covid-19 pandemic increases corruption risks in Ghana Report. Retrieved from: https://www.myjoyonline.com/covid-19-pandemic-increases-corru ption-risks-in-ghana-report/.

Myjoyonline.com (28 January, 2021) Covid-19 is not just a health and economic crisis, it is a corruption crisis' - Transparency International. Retrieved from: https://www.myjoyonline.com/covid-19-isnot-just-a-health-and-economic-crisis-it-is-a-corruption-crisis-transparency-international/.

Myjoyonline.com (9 July, 2021). Ghana's Covid 19 funds management lack transparency-CTAP, Retrieved from: https://www.myjoyonline.com/ghanas-covid-19-funds-management-lack-transparen cy-ctap/.

Neshkova, M. I., \& Kalesnikaite, V. (2019). Corruption and citizen participation in local government: Evidence from Latin America. Governance, 32(4), 677-693.

Newton, K. (2001). Trust, social capital, civil society, and democracy. International Political Science Review, 22(2), 201-214.

Owusu, G. M. Y., Koomson, T. A. A., Alipoe, S. A., \& Kani, Y. A. (2021). Examining the predictors of fraud in state-owned enterprises: an application of the fraud triangle theory. Journal of Money Laundering Control.

Oyebade, S. A. (2001). Applying the general systems theory to students' conflict management in Nigeria's tertiary institutions. Lagos Journal of Educational Administration and Planning, 1(1), 36-49.

Park, H., \& Blenkinsopp, J. (2011). The roles of transparency and trust in the relationship between corruption and citizen satisfaction. International Review of Administrative Sciences, 77(2), 254-274.

Pathak, R. D., Singh, G., Belwal, R., Naz, R., \& Smith, R. F. I. (2008). E-governance, corruption and public service delivery: A comparative study of Fiji and Ethiopia. Joaag, 3(1), 65-79.

Pellegata, A., \& Memoli, V. (2018). Corruption and satisfaction with democracy: The conditional role of electoral disproportionality and ballot control. European Political Science Review, 10(3), 393-416.

Plomp, T., \& Pelgrum, J. (1993). Implementation of Innovation in 21 Educations Systems the Study of Computers in Education.

Redford, E. S. (1969). Democracy in the administrative state. Oxford University Press.

Richardson, L. (2012). Political Corruption and Its Effects on Civic Involvement

Rose-Ackerman, S. (2021). Corruption and COVID-19. EUNOMÍA. Revista En Cultura De La Legalidad, 20, 16-36.

Slattery, G., \& Brito, R. (2020). The Ventilators Never Came: How Graft Hampered Brazil's COVID-19 Response.

Songsore, J. (2003). Regional development in Ghana: The theory and the reality. Woeli Pub. Services. 
Thomas, C. W. (1998). Maintaining and restoring public trust in government agencies and their employees. Administration \& Society, 30(2), 166-193.

Tschannen-Moran, M., \& Hoy, W. K. (2000). A multidisciplinary analysis of the nature, meaning, and measurement of trust. Review of Educational Research, 70(4), 547-593.

World Health Organization (2021), Retrieved from https://covid19.who.int/ on 20/04/2021.

Wu, M. (2010). Structural equation model-use and application of AMOS. Chongqing University Press.

Xinhua (Xinhua, 2021, March 21) 3 arrested for allegedly stealing COVID-19 vaccines in Ghana. Retrieved from: https://africa.cgtn.com/2021/03/21/3-arrested-for-allegedly-stealing-covid-19-vacci nes-in-ghana.

Yeboah-Assiamah, E., \& Alesu-Dordzi, S. (2016). The calculus of corruption: A paradox of 'strong'corruption amidst 'strong'systems and institutions in developing administrative systems. Journal of Public Affairs, 16(2), 203-216.

Zakaria, P. (2013). Is corruption an enemy of civil society? The case of Central and Eastern Europe. International Political Science Review, 34(4), 351-371.

Zhu, Q., Cordeiro, J., \& Sarkis, J. (2013). Institutional pressures, dynamic capabilities and environmental management systems: Investigating the ISO 9000-Environmental management system implementation linkage. Journal of Environmental Management, 114, 232-242.

Publisher's Note Springer Nature remains neutral with regard to jurisdictional claims in published maps and institutional affiliations. 